\title{
Engaging with End-Users of Independent Living Technology in Scotland... The Experience of The Blackwood Foundation
}

\author{
David Jarrold $^{1}$, Matt-Mouley Bouamrane ${ }^{2}$ \\ ${ }^{1}$ Blackwood Foundation, Edinburgh, Scotland \\ ${ }^{2}$ University of Glasgow, Scotland \\ College of Medical, Veterinary and Life Sciences, \\ Academic Unit of General Practice and Primary Care \\ Institute for Health and Well-Being, \\ $1_{\text {davidj@mbha.org.uk }}$ \\ ${ }^{2}$ Matt-Mouley.Bouamrane@glasgow.ac.uk
}

\begin{abstract}
We report on the recent activities of the Blackwood Foundation and specifically on a series of engagement workshops with the public. We organised 11 workshops across Scotland, which ran between 24 August and 19 October 2010. We sought to engage with people in order to explore how design and technology may enhance, or inhibit, independent-living. This involved speaking at length to over a 100 people around various aspects of home design and technology. We asked people to share their experiences and provide examples of design that delighted and frustrated them. We also asked them about their opinions about the best and worst technologies in relation to independent living. The discussions sought to explore and identify why certain devices worked well, why others did not, and what alternatives existed. Generally we sought to identify generic design principles which could be used to improve the experience of end-users of independent living technology.
\end{abstract}

Keywords: User-Engagement ; Independent Living Technology ; Accessible Interaction Design \& Technology for special needs \& the Home environment

\section{Introduction}

Design in the domestic context has a major impact on independent living and, over the last 10 to 15 years, new build standards have improved significantly [1-3]. Doors are wider, sockets are higher, switches are lower and overall accessibility has greatly improved.

However, in our experience, many people with a supportneed still do not usually live in a new build home with adequate design. This suggests a need to improve retro-fit" so- lutions and "universal adaptations" to support and enhance independence.

Technology offers a solution to a significant resource gap $[4,5]$. As our populations are ageing, improved health care extends the life expectancy of the general populations, as well as that of those with long term conditions and special needs. Therefore, the demands for independent living support are growing as well as becoming more complex [6,7]. This is occurring at a time when public finances are being squeezed and the working-age population - on which the rest of the population depends for financial support and provision of services - is decreasing. There is therefore an increasing gap in the availability of financial resources as well as a shortage of people willing or capable of providing support.

While technology is not a panacea on its own, it does have a significant role to play in supporting independent living now and in the future $[8,9]$.

We here report on our recent activities and specifically on a series of engagement workshops with the public in Scotland which ran between 24 August and 19 October 2010. During these workshops, we sought to engage with people to explore how design and technology enhance, or inhibit, independent living.

We begin this article with a background description of the Blackwood Foundation in section II. We describe our experience of engagement with the end users of independent-living technology in section III. We discuss key findings and lessons learnt in section IV and conclude with plans and directions for future activities and engagements. 


\section{Background}

\subsection{The Blackwood Foundation}

The Blackwood Foundation is a Scottish based charity working to support and enhance independent living ${ }^{1}$. It is an independent subsidiary of Margaret Blackwood Housing Association, which is one of the leading providers of affordable and accessible housing for people with special needs in Scotland $^{2}$. The focus of the Blackwood Foundation is (i) design and (ii) technology. Our interest in design includes the structure and layout of the home, fixtures and fittings, aids and adaptations, and household products. Our interest in technology incorporates both specific assistive technologies and more general, "off the shelf" devices. In other words, anything which may be useful to support and enhance independence. The Blackwood Foundation believes the key to developing better domestic design and more appropriate and usable technology lies in the engagement of end users.

\subsection{Capability Scotland}

Capability Scotland is a Scottish based charity working with people with special needs, their families and carers throughout Scotland ${ }^{3}$. In addition to providing a range of modern flexible services, the charity is also a campaigning organisation, committed to ensure people with special needs enjoy similar levels of rights and services as any other members of society.

\subsection{Ownership Options in Scotland}

Ownership Options provides a unique public access service to all people with special needs throughout Scotland ${ }^{4}$. It specialises in participatory action research, learning about the housing problems people with special needs face by directly assisting them, and using that knowledge to effect changes in policies and practice. It (i) assists, advises and supports people with special needs when faced with purchasing a property, (ii) provides information, advice and training on housing and disability issues to the public, private and voluntary sectors to improve the services to people with special needs and (iii) raise the awareness of the problems people with special needs face in relation to their housing and highlight the solutions and opportunities that exist.

We now describe a series of engagement workshops with the public in Scotland which ran between 24 August and 19 October 2010. During these workshops, we sought to

\footnotetext{
${ }^{1}$ http://www.mbha.org.uk/blackwood-foundation/

2 http: //www.mbha.org.uk/

${ }^{3}$ http: //www. capability-scotland.org.uk/

${ }^{4}$ http://ownershipoptions.org.uk
}

engage with people to explore how design and technology enhance - or inhibit - independent living.

\section{End-Users Engagement Work-shops}

\subsection{Partners}

We created and ran the series of workshops in partnership with Capability Scotland, bringing in their experience and expertise in consultation and engagement. Ownership Options in Scotland captured and recorded the workshop feedback and the University of Glasgow provided academic input: a researcher from the Strathclyde Centre for Disability Research analysed and compiled the feedback from the workshops into a research report: "Design and Technology as an Aid to Living Independently".

\subsection{Workshops Description}

We delivered 11 workshops across Scotland, from Kirkwall on Orkney to Peebles in the Borders, and consulted over 100 people in detail. The locations and dates of the workshops, along with the number of attendee at each venue, are detailed in table 1 . Each workshop lasted between 4-6 hours, starting at 10am and finishing by $4 \mathrm{pm}$. The workshops concentrated on design and technology and the format was relatively informal. Following an introduction of the aims of the workshops we looked at design and technology in turn, design in the morning and technology in the afternoon. We asked people for their examples of design that delighted and frustrated them. We also asked people about their best and worst technologies in relation to independent living. Participants had a brief discussion in pairs or threes to generate ideas and then we asked each person to feed back in turn so that everyone had the opportunity to contribute. The discussions then went deeper to find out why things worked well, why they didn't, what the alternatives were and how things could be improved. The workshops were facilitated jointly by the Blackwood Foundation and Capability Scotland. There was significant interest from a variety of professionals in the workshops, including academics, housing association staff and occupational therapists. We did not want to inhibit participation by people in the workshops but at the same time we recognized the benefits of professionals being able to hear first hand from the people they work with and design services for. We therefore created two observer slots at each workshop. Observers did not participate in the discussion but they had the opportunity to talk with participants during breaks and over lunch. 
TABLE I. WORKSHOP SUMMARY

\begin{tabular}{|c|c|c|}
\hline \multirow{2}{*}{ PLACE } & \multicolumn{2}{|c|}{ WORKSHOPS } \\
\hline & Date & Participants \\
\hline Kirkwall & 24 August 2010 & 7 \\
\hline Inverness & 26 August 2010 & 7 \\
\hline Skye & 30 August 2010 & 6 \\
\hline Aberdeen & 29 September 2010 & 8 \\
\hline Dundee & 30 September 2010 & 5 \\
\hline Peebles & 5 October 2010 & 6 \\
\hline Stirling & 7 October 2010 & 14 \\
\hline Glasgow & 11 October 2010 & 8 \\
\hline Glasgow & 12 October 2010 & 15 \\
\hline Edinburgh & 14 October 2010 & 14 \\
\hline Edinburgh & 16 October 2010 & 8 \\
\hline $\begin{array}{l}\text { Additional } \\
\text { Feedback }\end{array}$ & & 4 \\
\hline
\end{tabular}

Figure 1. Workshops summary

\section{Experience \& Lessons learnt}

\subsection{End-Users Feed-Back}

It was clear from the workshops that many people with special needs are unhappy with their inaccessible housing, and that many of the designs and technologies that they live with are not ideal. This is exacerbated by the lack of consultation with them and their exclusion from the design of solutions. Often there are simple solutions to problems and people with special needs are the experts in designing improvement to their own lives. It is clear that people with special needs often require adapted and appropriate design in order to meet their needs and support their independence. However, people with special needs are seldom included in the development or decision making process when technologies and designs are being tailored for them. Furthermore, impairment is individual and varied and as such what works for one person does not work for another, therefore it is even more crucial that people with special needs be consulted in what enables their independence in their homes.

The key points that emerged from the workshops were:

- People with special needs want to be involved, decide, choose and be consulted on what best works for them particularly when it comes to accessing their home environment.

- Solutions that support living independently should take into account a person special needs and home environment, whether they live with other people with special needs, people without special needs, children, pets and so forth.
- People with special needs want to be able to enjoy their homes, be house proud and take pleasure from the domestic environment in which they live. Although adaptations may be required in order to enable independence it is essential that people with special needs are recognised as appreciating design and aesthetics.

- Participants felt that many products aimed specifically at people with special needs were an exercise in 'reinventing the wheel' and often solutions to problems could be found generically and in the mainstream.

- The workshops showed that often people with special needs are not aware that solutions to their design or technology problems are available and so a general lack of information for people with special needs is apparent.

- Some participants favoured low-tech simple solutions to everyday problems and often found that complex hi-tech products were not useful in supporting independence. Hitech solutions were often favoured by participants with a visual impairment as high technology is often most appropriate in supporting living independently. Furthermore high technology was favoured by those who used powered mobility aids but it was highlighted that this technology could be unreliable.

- People with special needs are not a homogenous group and as such people with special needs often require tailored solutions to individual problems. Similarly, specific technologies designed for people with special needs are not always appropriate and a 'one size fits all' approach does not work. Impairment can vary greatly from one person to the next, impairment is not static but changes over time therefore in many cases people's needs change throughout their lives as their disability changes. As such design and technology must meet these changing needs.

The workshop findings showed that the Blackwood Foundation's founding principle of involvement of people with special needs is crucial in advancements in design and technology. People with special needs should be consultants in this area, recognised as experts and decision makers in their own lives and active participants in society. People with special needs are not passive receivers of design and technologies but active members of society who participate through innovation, adaptation and choice.

\subsection{Key lessons}

The workshop series was inspired by contact with the tenants and service users of Margaret Blackwood Housing Association. Their ingenuity and creativity to adapt products and complete daily tasks was astounding. The Blackwood Foundation wanted to know if this was common to a wider range of people and also why it was still so necessary 
when inclusive design principles should be improving environments and products. From an organizational perspective the key lessons the Blackwood Foundation took from this research were:

- People with special needs and older people are without doubt crucial and underutilized experts in independent living.

- The opportunities for people to share solutions with their peers, and to impact on the design and development process, are limited.

- There is a sporadic level of awareness of what adaptations, products and technologies exist to support independent living, and how these solutions can be sourced.

\section{Discussion \& Future Activities}

\subsection{Challenges}

The workshops findings present the Blackwood Foundation with two main challenges. Firstly we want to create an opportunity for end users to engage in and influence the development process of designs and products that support independent living. Secondly we want to provide an information portal through which people can gain access to information on the goods and services that exist to support their independence. To meet these challenges and achieve these outcomes the Blackwood Foundation is looking to develop two online facilities, a social media site and a consumer choice site.

\subsection{Social Media}

Building on the outcomes from the workshops, social media presents the Blackwood Foundation with an opportunity to establish a long term channel of information on design, technology and independent living that will inform our work. A social media site will perform two main functions. Firstly it will provide people with a forum to exchange views, information, advice and learning. One of the most powerful aspects of the workshops was the opportunity for peer learning by people with shared or similar circumstances. Secondly the social media site will give the Blackwood Foundation a tool which it can use to link designers and developers with end users. This gives people an opportunity to engage in the design and development process and it gives organizations a service through which they can access a specific profile of end user. In addition the Blackwood Foundation can use the site to support engagement of people in research projects by creating private groups and forums linked to specific projects. A significant element of social media is that the content is user generated. The Blackwood Foundation expects the site to grow organically and therefore reflect the needs, aspirations and priorities of end users.

\subsection{Consumer Choice Website}

There is a change happening in the care field. People are moving from being recipients of care to being consumers, responsible for structuring and purchasing their own care and support provision. This is a significant change that presents both opportunities and challenges for people.

There are a limited number national organisations that provide advice on independent living aids and telecare devices. Similarly there are a small number of suppliers that provide an on-line service. However, there is no one stop shop for advice and supply which makes it difficult for people to source information and products. The Blackwood Foundation is looking at developing a consumer choice site to fill this void.

This site will provide a single point of information that links to advice organisations so people can make an assessment of what would be best for them. It will also provide an opportunity for people to purchase products. By creating a comparison site we hope to provide a further route to market for existing suppliers, and establish a route to market for organisations that currently do not sell direct to the public. It is hoped that in addition to providing a coordinated point of information this site will also stimulate the creation of new products leading to a wider choice for consumers.

The Blackwood Foundation is establishing partners to assist in achieving these aims. The launch of the social media site is planned for May 2011 and the consumer choice site is scheduled for creation by the end of the year.

\section{Conclusion}

We have reported the activities of the Blackwood Foundation around a series of workshops designed to engage with end-users of independent living technology across Scotland.

We found that:

The level of ingenuity on the part of people with special needs to find fixes and work-arounds for many tasks was inspiring. Domestic design often continues to hamper independent living. The level of engagement with technology was high. There was a strong desire for personalization of aids and adaptations so that people were not defined by their disability or condition and were able to express their individuality. The opportunities for people to engage in the development process for designs and technologies were limited. Sources of information relating to independent living aids and products are fragmented and difficult to navigate. 


\section{ACKNOWLEDGMENT}

The authors would like to thank all those who helped with and participated in the engagements workshops, and in particular all those who engaged with the Blackwood Foundation during the workshop. We would also particularly like to thank Elspeth Molony (Capability Scotland), Moira Bayne (Ownership Options in Scotland) and Phillippa Robertson-Rieck and Prof. Nick Watson from the Strathclyde Centre for Disability Research, School of Social and Political Sciences, University of Glasgow.

\section{References}

[1] Goldsmith, S (1997) Designing for the Disabled: the new paradigm, London, Architectural Press

[2] Ratzka, A (1990) 'The Swedish Experience' in Laurie, L Building our Lives: Housing, Independent Living and Disabled People, London, Shelter

[3] Stephen M. Golant and Joan Hyde (eds), The Assisted Living Residence: A Vision for the Future, Johns Hopkins University Press, Baltimore, Maryland, 2008, 464 pp.

[4] Ganer, Katrin and Michael Conrad, ICT enabled independent living for elderly - A status-quo analysis on products and the research landscape in the field of Ambient Assisted Living (AAL) in EU-27. Institute for Innovation and Technology, VDI/VDE Innovation, Technik GmbH, and the AALIANCE project, 2010

[5] Koch, S. Home telehealth-Current state and future trends International Journal of Medical Informatics, 2006, 75, 565 $-576$

[6] Building A Society of All Ages: Choices for Older People, Department of Work and Pensions, 2009

[7] Shaping the Future of Care Together, Care and Support green paper, Department of Health, 2009.

[8] Heinzelmann, Paul J.; Nancy E Lugn and Joseph C Kvedar. Telemedicine in the future, J Telemed Telecare 2005;11:384390

[9] McLean, Susannah; Denis Protti and Aziz Sheikh, Telehealthcare for long term conditions, BMJ 2011;342:d120 